\title{
Detection and quantification of gas-phase oxidized mercury compounds by GC/MS
}

\section{Colleen P. Jones et al.}

Correspondence to: Seth N. Lyman (seth.lyman@usu.edu)

The copyright of individual parts of the supplement might differ from the CC-BY 3.0 licence. 


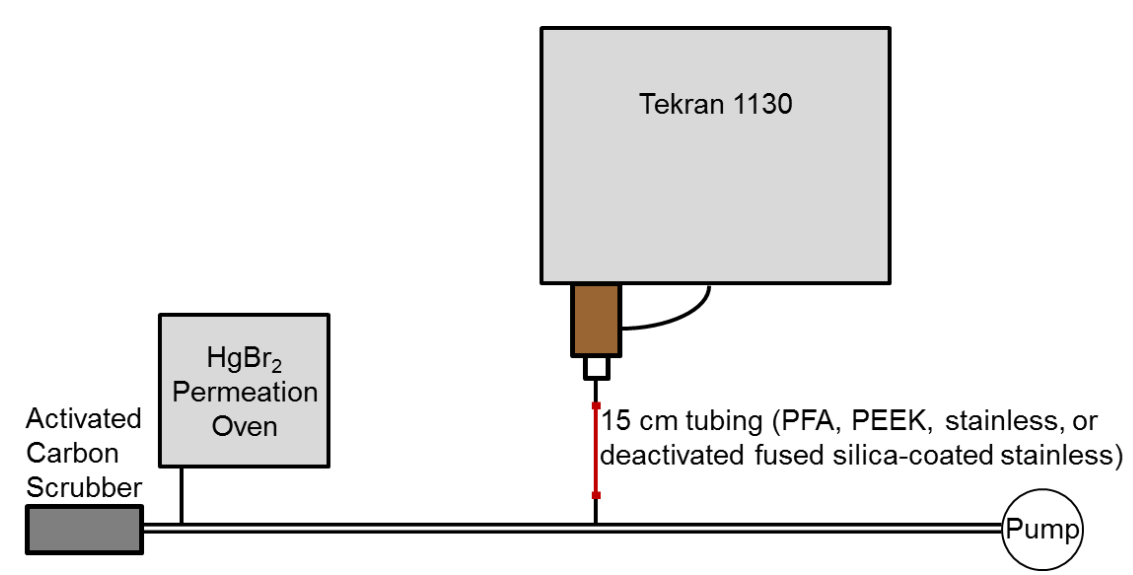

Figure S1. Diagram of manifold for testing transmission of $\mathrm{HgBr}_{2}$ through tubing materials. 